DOI 10.5012/bkcs.2011.32.6.1936

\title{
Microstructure and Antibacterial Activity of Phosphonium Montmorillonites
}

\author{
Agui Xie, Wenyan Yan, Xianshen Zeng, Guangjian Dai, Shaozao Tan, Xiang Cai, and Ting Wu \\ Department of Chemistry, Jinan University, Guangzhou, 510632, PR China. *E-mail: tanshaozao@163.com \\ Received November 24, 2010, Accepted April 21, 2011
}

\begin{abstract}
Phosphonium montmorillonites (P-MMTs) were prepared by intercalating dodecyl tributyl phosphonium salt into sodium montmorillonite (Na-MMT) through an ion-exchange method. Microstructure and antibacterial activity of phosphonium montmorillonites were studied by FT-IR, TGA, XRD and Minimum Inhibitory Concentration (MIC), respectively. The results show that phosphonium montmorillonites exhibit higher thermal stability than conventional ammonium montmorillonites, the onset temperature of decomposition is higher than $300^{\circ} \mathrm{C}$, and the basal spacing of phosphonium montmorillonites is enlarged compared to that of sodium montmorillonite. Phosphonium montmorillonites also show good antibacterial activity with the MIC against $E$. coli and $S$. aureus of 150 and $50 \mathrm{mg} \cdot \mathrm{L}^{-1}$, respectively.
\end{abstract}

Key Words : Composite materials, Phosphonium montmorillonite, Dodecyl tributyl phosphonium ion, Microstructure, Antibacterial activity

\section{Introduction}

Organoclays have been used as agents by environmental control to enhance oil recovery ${ }^{1,2}$ and reduce herbicidal leaching, ${ }^{3}$ or have been used as fillers in nanocomposites. ${ }^{4,5}$ Most of the commercially available organoclays are alkyl ammonium modified clays, but their applications in engineering plastics are restricted due to the low heat resistant temperature of about $250{ }^{\circ} \mathrm{C}$. Other cations, such as phosphonium, pyridinium and imminium are the excellent modified agents due to their higher thermal stability. Patel et $a l .{ }^{6}$ has found that phosphonium montmorillonites (PMMTs) showed enhanced thermal stability $\left(300-400{ }^{\circ} \mathrm{C}\right)$.

However, to the best of our knowledge, there have been few reports on the antibacterial activity of P-MMTs. The organoposhonium surfactants are the excellent antibacterial agents, but will pollute the environment if directly used. Herrera and co-workers ${ }^{7}$ reported that cetylpyridinium modified montmorillonites could facilitate the removal of bacteria from various water sources. Intercalating the organoposhonium surfactants into organoclays are one of the best ways to restrain bacterial instead of polluting the environment. Here, a surfactant of dodecyl tributyl phosphonium ion with excellent bactericidal activity has been selected and intercalated into montmorillonite to obtain phosphonium montmorillonites (P-MMTs) with long-acting antibacterial activity, and the microstructure, antibacterial property and thermal properties of P-MMTs have been investigated.

\section{Experimental Procedure}

Materials. The sodium montmorillonite (Na-MMT) rich bentonite clay with a cation-exchange capacity (CEC) of $100 \mathrm{meq} / 100 \mathrm{~g}$ on dry basis (dried at $110^{\circ} \mathrm{C}$ ) was obtained from Hongyu Clay Co., Ltd. (Zhejiang, China). Dodecyl tributyl phosphonium bromide (DDTBPBr) of C.R. grade was supplied by Qingte Chemical Industry Co., Ltd. (Shanghai, China). Mueller-Hinton broth and nutrient agar culture medium were supplied by Huankai Microorganism Co., Ltd. (Guangzhou, China). E. coli ATCC25922 and S. aureus ATCC 6538 were supplied by Guangdong Institute of Microbiology (Guangzhou, China).

Preparation. P-MMTs were prepared by an ion-exchange reaction. Briefly, Na-MMT powder (10.0 g) was dispersed in $190 \mathrm{~mL}$ volumes of deionized water and blended for $0.5 \mathrm{~h}$ at $60^{\circ} \mathrm{C}$. Then, $0.25,0.5,1.0$ and 1.5 times DDTBPBr of NaMMT CEC were slowly added under continuous stirring. The reaction was allowed to proceed at $70{ }^{\circ} \mathrm{C}$ for $3 \mathrm{~h}$. The resulting precipitate was collected by centrifugation and washed to be free from bromonium ions, and was dried under vacuum at $65{ }^{\circ} \mathrm{C}$ for $24 \mathrm{~h}$ to obtain a solid product, then pulverized to pass through 300 mesh sieve. The PMMTs were designated as P-MMT1, P-MMT2, P-MMT3 and P-MMT4.

Characterization. FT-IR spectra were measured with a Perkin-Elmer Spectrum Gx spectrophotometer from samples in $\mathrm{KBr}$ pellets. TGA, DTG were conducted with a thermal analyzer (NETZSCH TG 209) under air flow; the temperature range of the measurements was $40-950{ }^{\circ} \mathrm{C}$ and the scanning rate was $10^{\circ} \mathrm{C} / \mathrm{min}$. XRD patterns of the samples were recorded on a D/max-1200 diffractometer $(40 \mathrm{kV}, 40$ $\mathrm{mA}, \mathrm{Cu} \mathrm{K} \alpha, \lambda=0.1541 \mathrm{~nm})$. For antibacterial tests, the MIC of the samples against $E$. coli and $S$. aureus was estimated by a two-fold diluting method, ${ }^{8}$ the tests were run in triplicate.

\section{Results and Discussion}

FT-IR Assignment. In the FTIR spectrum of Na-MMT rich bentonite clay (Fig. 1), the bands near 3600 and 3400 $\mathrm{cm}^{-1}$ are indicative of montmorillonite. ${ }^{7}$ The broad band centered at $3437 \mathrm{~cm}^{-1}$ is due to the $-\mathrm{OH}$ stretching mode of 


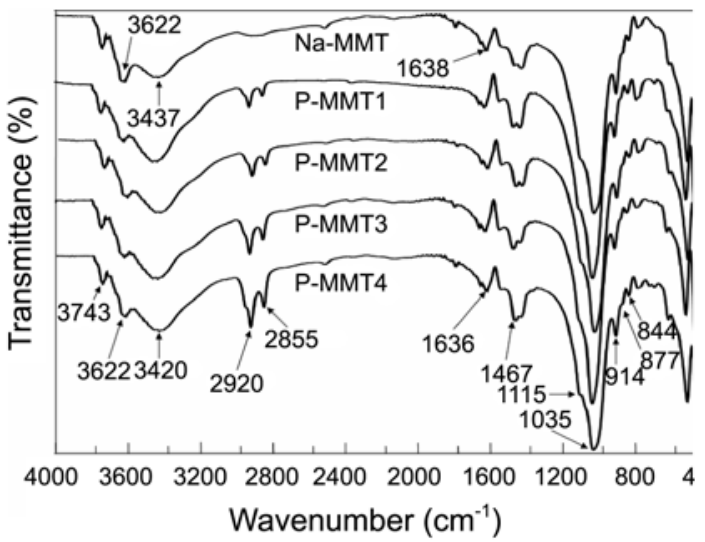

Figure 1. FTIR spectra of Na-MMT and P-MMTs.

interlayer water. The band at $3622 \mathrm{~cm}^{-1}$ is due to the $-\mathrm{OH}$ stretching mode of $\mathrm{Al}-\mathrm{OH}$ or $\mathrm{Si}-\mathrm{OH}$ of montmorillonite. The overlaid absorption peak in the region of $1638 \mathrm{~cm}^{-1}$ may be attributed to the $-\mathrm{OH}$ bending mode of adsorbed water. The characteristic peak at $1115 \mathrm{~cm}^{-1}$ is due to $\mathrm{Si}-\mathrm{O}$ stretching, out-of-plane Si-O stretching mode for Na-MMT. The band at $1035 \mathrm{~cm}^{-1}$ is attributed to Si-O stretching (in plane) vibration for layered silicates. The IR peaks at 914, 877 and $844 \mathrm{~cm}^{-1}$ are attributed to $\mathrm{Al}-\mathrm{Al}-\mathrm{OH}, \mathrm{Al}-\mathrm{Fe}-\mathrm{OH}$ and $\mathrm{Al}-\mathrm{Mg}$ $\mathrm{OH}$ bending vibration.

Compared with Na-MMT, the peaks at 2920 and $2855 \mathrm{~cm}^{-1}$ of P-MMTs (Fig. 1) may be ascribed to the asymmetric and symmetric vibrations of the methylene groups $\left(\mathrm{CH}_{2}\right)_{n}$ of the aliphatic chain. ${ }^{7}$ Therefore, the existence of the organic groups in P-MMTs was proved. In other words, DDTBP was intercalated into Na-MMT.

Thermal Characterization. The TGA, DTG and DTA curves of Na-MMT, P-MMTs are shown in Figure 2, Figure 3 and Figure 4, respectively. According to the weight loss in TGA curve and the prominent endotherm peakings in DTA curve, the decomposition of Na-MMT clearly occurs in two general regions below $800^{\circ} \mathrm{C}^{9}$ : (1) evolution of free (absorbed) and interlayer water residing between the aluminosilicate layers and comprising the hydration spheres of the cations between 50 and $200^{\circ} \mathrm{C}$; (2) dehydroxylation of the aluminosilicate lattice between $500{ }^{\circ} \mathrm{C}$ and $700{ }^{\circ} \mathrm{C}$. At the same time, the TGA and DTA curves of P-MMTs may be conveniently divided into three regions ${ }^{10}$ : (1) evolution of absorbed water and gases below $200{ }^{\circ} \mathrm{C}$; (2) evolution of the organic substances between 200 and $500^{\circ} \mathrm{C}$; (3) dehydroxyl-

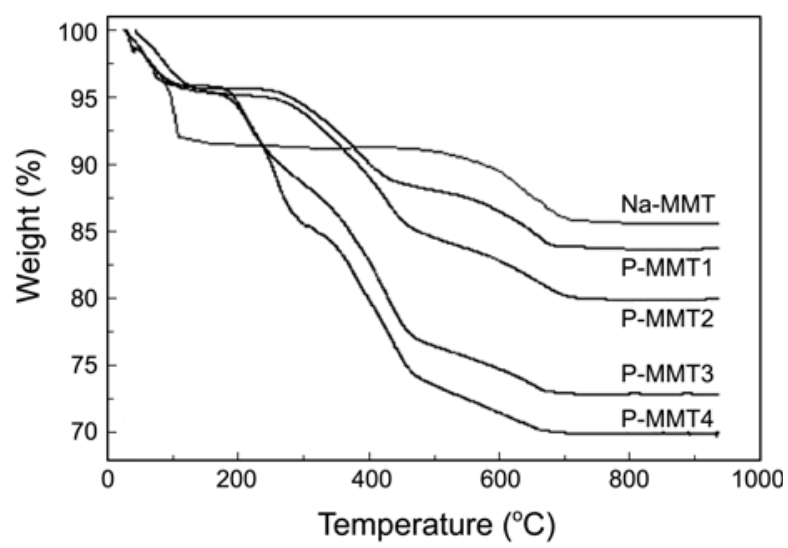

Figure 2. TGA curves of Na-MMT and P-MMTs.

ation of the aluminosilicate between 500 and $700{ }^{\circ} \mathrm{C}$.

In contrast with the Na-MMT, the water content (weight loss) of P-MMTs in range $(1)\left(50-200^{\circ} \mathrm{C}\right)$ is lower due to the hydrophobic nature of DDTBP cation. In addition, the organic content of P-MMTs can be determined in range (2) $\left(200-500^{\circ} \mathrm{C}\right)$, and the DDTBP cation content of P-MMT1, P-MMT2, P-MMT3 and P-MMT4 is 7.34, 13.37, 22.13 and $23.05 \mathrm{wt} \%$ (Table 1), respectively. As might be expected, the DTA curves in range $(2)\left(200-500{ }^{\circ} \mathrm{C}\right)$ are also characterized by a series of exothermic peaks. Following Xie et $a l .{ }^{10}{ }^{1}$ the onset temperature of the first (prominent) exotherm is taken to represent the point at which the intercalated organic substance begins to decompose. The onset temperature of decomposition for P-MMT1, P-MMT2, P-MMT3 and P-MMT4 is $338,330,310$ and $307^{\circ} \mathrm{C}$, respectively

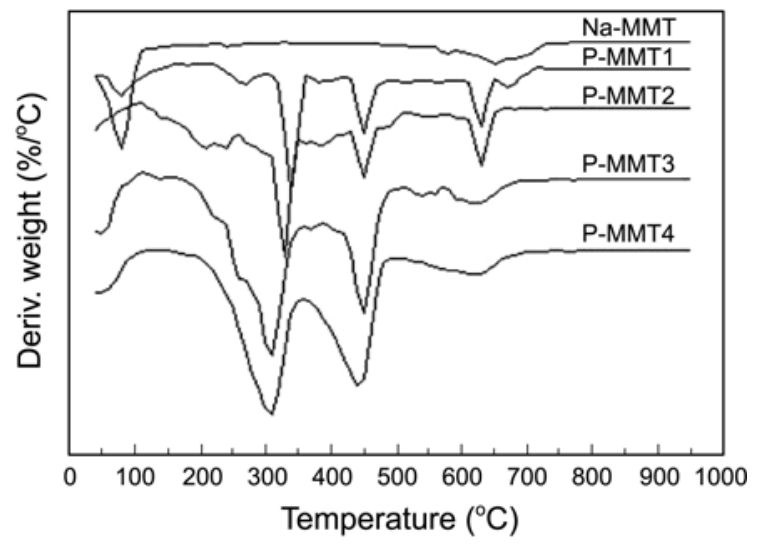

Figure 3. DTG curves of Na-MMT and P-MMTs.

Table 1. Basal spacing, thermo-analytical characteristics and antibacterial activity of Na-MMT and P-MMTs

\begin{tabular}{|c|c|c|c|c|c|c|}
\hline \multirow{2}{*}{ Sample } & \multirow{2}{*}{$\begin{array}{c}\text { Basal } \\
\text { spacing/nm }\end{array}$} & \multirow{2}{*}{$\begin{array}{l}\text { Organic added }{ }^{a} / \text { Times } \\
\text { of Na-MMT CEC/wt \% }\end{array}$} & \multirow{2}{*}{$\begin{array}{l}\text { Organic content }{ }^{b} / \text { Times } \\
\text { of Na-MMT CEC/wt } \%\end{array}$} & \multirow{2}{*}{$\begin{array}{l}\text { Onset temperature } \\
\text { of decomposition } /{ }^{\circ} \mathrm{C}\end{array}$} & \multicolumn{2}{|c|}{$\mathrm{MIC}^{c} /\left(\mathrm{mg} \cdot \mathrm{L}^{-1}\right)$} \\
\hline & & & & & E. coli & S. aureus \\
\hline Na-MMT & 1.227 & - & - & - & $>10000$ & $>10000$ \\
\hline P-MMT1 & 1.429 & $0.250 / 51.52$ & $0.018 / 7.34$ & 338 & 500 & 200 \\
\hline P-MMT2 & 1.492 & $0.500 / 69.33$ & $0.034 / 13.37$ & 330 & 300 & 100 \\
\hline P-MMT3 & 1.916 & $1.000 / 81.88$ & $0.063 / 22.13$ & 310 & 150 & 50 \\
\hline P-MMT4 & 2.063 & $1.500 / 87.15$ & $0.066 / 23.05$ & 307 & 150 & 50 \\
\hline
\end{tabular}

$a_{\mathrm{wt}} \%=m_{\text {Organic added }} /\left(100+m_{\text {Organic added }}\right) .{ }^{b} \mathrm{TGA}$ weight loss between 200 and $500{ }^{\circ} \mathrm{C} . \mathrm{wt} \%=m_{\text {Organic content }} /\left(100+m_{\text {Organic content }}\right) .{ }^{c}$ mean $\pm \mathrm{MIC}, n=3$ 


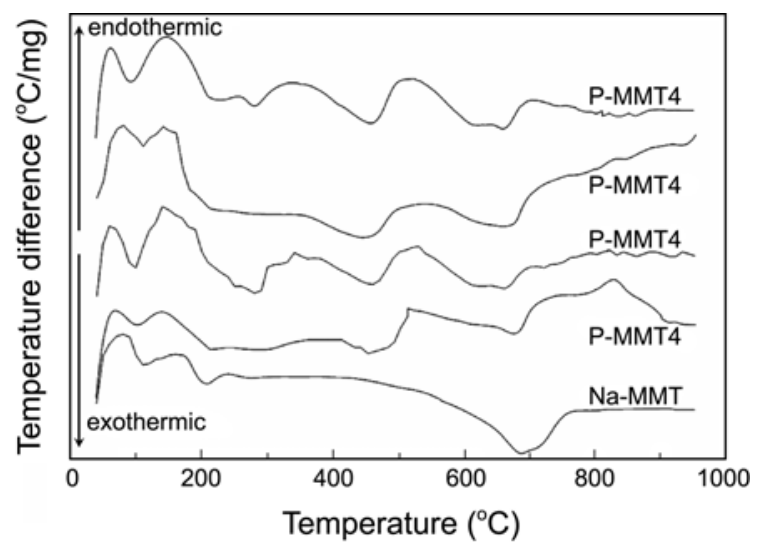

Figure 4. DTA curves of Na-MMT and P-MMTs.

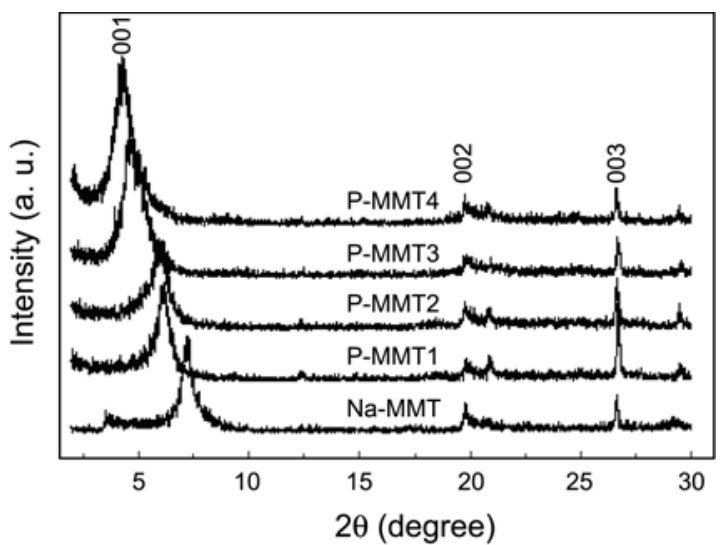

Figure 5. XRD spectrograms of Na-MMT and P-MMTs.

(Table 1). It therefore appears that the thermal stability of PMMTs decreases as the intercalated organic content increases whereas they are all higher than $300^{\circ} \mathrm{C}$. Thus P-MMTs have the potential to be used as nanofillers of engineering plastics with high processing temperature.

XRD Analysis. XRD spectrograms of Na-MMT and PMMTs are shown in Figure 5, and the corresponding basal spacing $\left(d_{001}\right)$ are seen in Table 1 . The XRD patterns of NaMMT and P-MMTs shows three obvious diffraction peaks of $(001),(002)$ and (003). In contrast with the $2 \theta$ values of $7.2^{\circ}\left(d_{110}=1.227 \mathrm{~nm}\right)$ for $(001)$ diffraction peak of NaMMT, a displacement of the diffraction peaks for P-MMTs toward lower angles is observed, and the basal spacing $\left(d_{001}\right)$ varies between 1.429 and $2.063 \mathrm{~nm}$. The values of $1.429 \mathrm{~nm}$ for P-MMT1 and $1.492 \mathrm{~nm}$ for P-MMT2 are consistent with a monolayer arrangement of the quaternary phosphonium cations in the interlayer space, while those of $1.916 \mathrm{~nm}$ for P-MMT3 and $2.063 \mathrm{~nm}$ for P-MMT4 indicate a bilayer to pseudotrilayer arrangement of intercalated surfactants. ${ }^{1}$

Antibacterial Activity. The antibacterial activity of NaMMT and P-MMTs against E. coli and $S$. aureus is shown in Table 1. Na-MMT shows poor antibacterial activity, because the MIC values against the two kinds of microorganisms are all more than $10,000 \mathrm{mg} \cdot \mathrm{L}^{-1}$. For P-MMTs, they show good antibacterial activity against $E$. coli and $S$. aureus, and the MIC decreases or the antibacterial activity increases with the enhancement of the organic content of P-MMTs. In the case of P-MMT3 and P-MMT4, because they have almost the same organic content, they both show good and almost the same antibacterial activity and the MIC against $E$. coli and $S$. aureus is 150 and $50 \mathrm{mg} \cdot \mathrm{L}^{-1}$, respectively.

\section{Conclusions}

Phosphonium montmorillonites were prepared by intercalating dodecyl tributyl phosphonium into sodium montmorillonite through an ion-exchange method. The persistence of organic group indicates that dodecyl tributyl phosphonium is intercalated into sodium montmorillonite, and phosphonium montmorillonites exhibit excellent thermal stability with the onset temperature of decomposition above $300^{\circ} \mathrm{C}$. Also the basal spacing of phosphonium montmorillonites is enlarged compared to that of sodium montmorillonite. Moreover, phosphonium montmorillonites show good antibacterial activity against $E$. coli and $S$. aureus with the MIC of 150 and $50 \mathrm{mg} \cdot \mathrm{L}^{-1}$, respectively. Thus phosphonium montmorillonites are potentially useful materials for melt processing of antibacterial polymer/layered silicates nanocomposites.

Acknowledgments. This work has been supported by the National Natural Science Foundation of P. R. China (Nos. 20676049, 20871058, 20971028 and 21006038), the Foundation of Enterprise-University-Research Institute Cooperation from Guangdong Province and the Ministry of Education of China (No. 2008A010500005), the Foundation of Enterprise-University-Research Institute Cooperation from Guangdong Province and the Chinese Academy of Sciences (2010B090301036).

\section{References}

1. Kozak, M.; Domka, L. J. Phys. Chem. Solids 2004, 65, 441-445.

2. El-Nahhal, Y. Z.; Safi, J. M. J. Colloid Interf. Sci. 2004, 269, 265273.

3. Rytwo, G.; Tavasi, M.; Afuta, S.; Nir, S. Appl. Clay Sci. 2004, 24, 149-157.

4. Arroyo, M.; López-Manchado, M. A.; Herrero, B. Polymer 2003, 44, 2447-2453.

5. Yeh, J. M.; Liou, S. J.; Lin, C. Y.; Cheng, C. Y.; Chang, Y. W. Chem. Mater 2002, 14, 154-161.

6. Patel, H. A.; Somani, R. S.; Bajaj, H. C.; Jasra, R. V. Appl. Clay Sci. 2007, 35, 194-200.

7. Herrera, P.; Burghardt, R. C.; Phillips, T. D. Vet. Microbiol 2000, 74, 259-272.

8. Tan, S. Z.; Zhang, L. L.; Huang, L. H.; Zhou, J. E.; Liu, W. L. J. Ceram Soc. Jpn 2007, 115, 269-271.

9. Awad, W. H.; Gilman, J. W.; Nyden, M.; Harris, R. H., Jr.; Sutto, T. E.; Callahan, J.; Trulove, P. C.; Delong, H. C.; Fox, D. M. Thermochim. Acta 2004, 409, 3-11.

10. Xie, W.; Gao, Z.; Pan, W. P.; Hunter, D.; Singh, A.; Vaia, R. Chem. Mater 2001, 13, 2979-2990. 